\title{
A Learning Mode of Interactive Autonomy Based on the Smart Learning Environments Hao Zhang ${ }^{1, a}$, Tao Huang ${ }^{1}$,Yepei Xing ${ }^{1, a}$ and Heng Yang ${ }^{1, a}$

\author{
National Engineering Research Center for E-Learning, Central China Normal University(CCNU) \\ azhanghao@mail.ccnu.edu.cn
}

Keywords: Smart learning environment; interactive learning; constructivism; autonomous learning;

\begin{abstract}
With the development of the internet, autonomous learning like MOOC in network environment has been more and more popular. However, many problems have been discovered in these online autonomous learning. For example, it is difficult to provide a suitable learning environment for online learners. In this paper, we proposed a learning mode of interactive autonomy based on the smart learning environment that matches theory of constructivism and teaching principle. Compared with the traditional teaching mode, it realizes the personalized learning to develop students' ability in autonomous and collaborative learning.
\end{abstract}

\section{Introduction}

The generation of learners contact and use all kinds of digital devices at an early age in the 21 st century. They are more adapted to the digital environment ${ }^{[\mathrm{i}]}$. With the development of the internet, autonomous learning has become a hot research $^{[i i]}$ in recent years. MOOC is popular with teachers and students. Our learners like MOOC ${ }^{[i i i]}$ exceedingly. However, there are some things that need to develop such as the interaction mechanism, learning environment and the learner's own factors. Kinshuk also said, "Learning how to use platform to record information and provide suitable learning content, learning environment and support for learners while providing the best intervention time for teacher is a big challenge ${ }^{[i v] " . ~ I n ~ t h i s ~ a r t i c l e, ~ w e ~ e x p l o r e s ~ h o w ~ t o ~ i m p l e m e n t ~ a n ~ i n t e r a c t i v e ~ l e a r n i n g ~ b a s e d ~ o n ~ t h e ~ s m a r t ~ l e a r n i n g ~}$ environment.

\section{A Learning Mode of Interactive Autonomy Based on the Smart Learning Environments}

According to the framework of self-learning proposed by Zimmerman ${ }^{[\mathrm{v}]}$, autonomous learning is an interactive activity among learners, his/her behavior and learning environment, ${ }^{[\mathrm{vi}]}$ following the teaching principle of "being student-centered and teacher-led". Based on the teaching content, the teachers set up an autonomous learning environment to fit students' cognitive characteristics before class in STARC COURSE. It provides various learning tasks so that students could choose, mix and match them freely. The discussion on forum forms a collaborative learning environment and the difficult parts are also exposed. Further supplementary teaching will be provided to make these problems clear. Finally, students are asked to practice again to consolidate and strengthen the knowledge. The whole learning process is multi-interactive (the interaction among teachers, students and platforms) and accessible for the transmission and exchange of information, as shown in Fig 1.

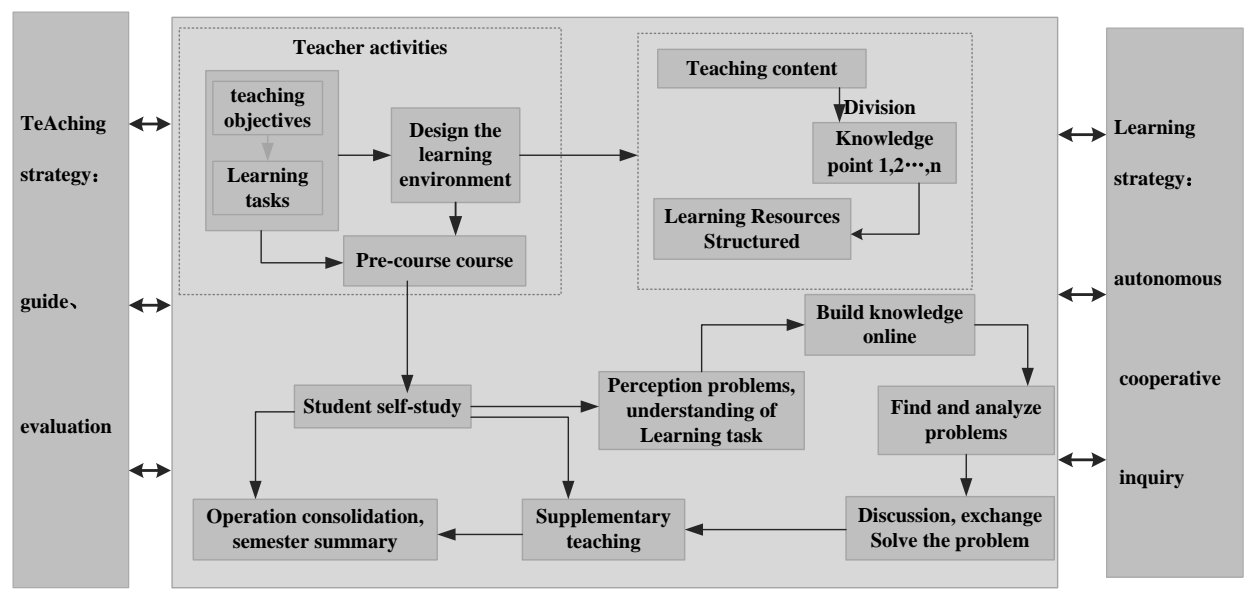

Fig. 1 A learning mode of interactive autonomy based on the smart learning environments

2.1 Determine the Teaching Objectives and Learning Tasks. Teacher's inspiration is the premise of interactive teaching. The teachers based on three things including the purpose of teaching, content and specific situation of students make teaching requirement and carry out teaching activities. It plays an essential role on judging a lesson.

2.2 Design Learning Environment. According to teaching objectives and requirements, teachers determine the knowledge point ${ }^{\text {[vii] }}$, as shown in Fig 2. 


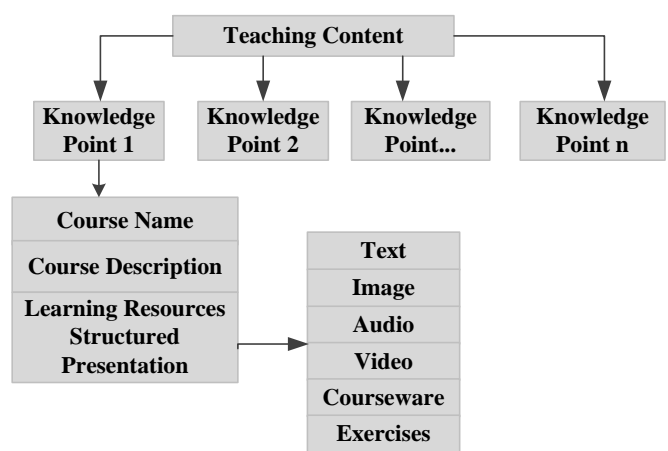

Fig. 2 Design learning environment

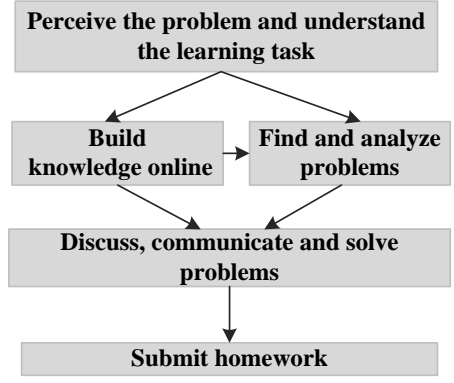

Fig. 3 Learner autonomy learning

The instructor creates each guide course around a specific knowledge point in "STARC COURSE". It is also important to design learning resources by analyzing curriculum objectives.

Each knowledge unit is composed of several points. As a result, we need different resources to explain every point. The resources should meet the following requirement: the content should be short; the target should be clear; each part is independent and interrelated [viii]. Learning resources could be in different types (video, audio, PowerPoint, pdf, documents, images, etc.). "STARC COURSE" provides Wiki and forum to achieve the interactive learning between students and teachers.

2.3 Autonomic Learning. It gives full play to the learner's subjectivity. Firstly, they perceive problems from different dimensions through the learning situation and feel free to express their views. Secondly, students can choose the learning content and complete the task accordingly before the deadline. A final discussions will be carried out on the forum to promote the communication between teachers and learners. During the whole process, students are constantly motivated and able to develop their learning ability, as shown in Fig 3.

2.4 Review and Supplementary of Knowledge. Teachers can observe how the students learn and decide a supplementary teaching by checking the number of exercises, the correct rate etc on the platform.

\section{Case of the Learning Model}

In this paper, it takes mathematics teaching as an example--Seventh-grade math "parallel line nature".

3.1 The Learning Task. The teachers upload resources. Then, students can directly download the knowledge list. The course provides many resources. For example, video, exercises and so on. Students are required to build a knowledge structure by learning these types of resources autonomously, as shown in Fig 4.

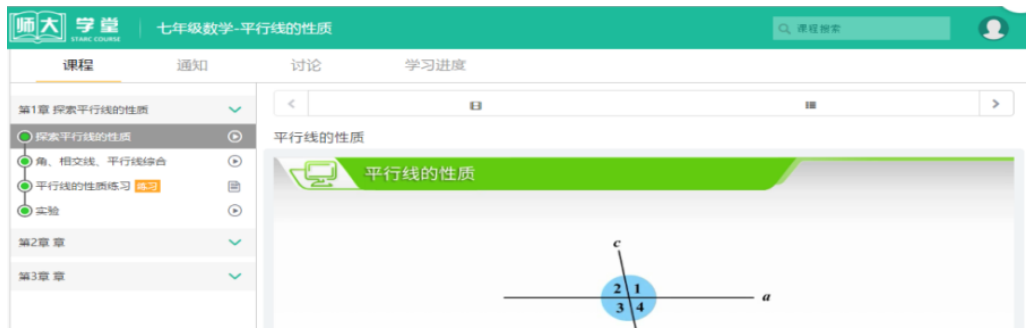

Fig. 4 Various types of teaching resources

3.2 Submit your Work and Feedback. Teachers put forward appropriate guidance to help students consolidate knowledge. Students can see scores and reviews from the teacher, and download all these documents. Teachers can check the process of completion in the progress page.

\section{An Analysis of the Application Effect of the Learning Model}

After the end of the seventh grade mathematics experiment, the questionnaire survey analyzes the attitude of the learners to the model teaching. The survey was conducted on the 115 students from Caoqiao middle in Suzhou, with 100\% recovery rate.

The survey results show that $20 \%$ of the students are very fond of this teaching and $50 \%$ of the students like this colorful teaching model. It is a breakthrough that the student were set as the main body in the interactive autonomous learning, as shown in Fig 5. 


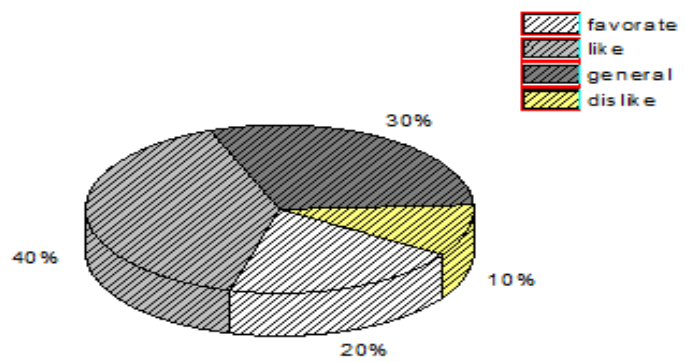

Fig. 5 Students' Attitude towards Interactive Autonomous Learning

4.1 The Analysis of Empirical Result From Table 1, the average score of the experimental class is higher. The advantage is obvious and there is a clear gap in the standard deviation. The performance of the experimental class has been significantly improved. However, more schools in different regions will be needed in the follow-up verification.

Table 1 Analysis of test scores

\begin{tabular}{|l|l|l|l|l|l|l|}
\hline Test & Class & Number & $\begin{array}{l}\text { Average } \\
\text { score }\end{array}$ & $\begin{array}{l}\text { Standard } \\
\text { deviation }\end{array}$ & T-test & P value \\
\hline $\begin{array}{l}\text { Final } \\
\text { exam }\end{array}$ & Experimental & $\mathrm{N}=63$ & $\mathrm{X}=89.55$ & $\mathrm{~S}=11.510$ & 0.879 & 0.003 \\
\cline { 2 - 5 } & Control & $\mathrm{N}=52$ & $\mathrm{X}=83.94$ & $\mathrm{~S}=12.250$ & & \\
\hline
\end{tabular}

\section{Summary}

Most of the students enjoy and accept this kind of teaching mode. The abundant learning resources and convenient communication are helpful for the teaching. This is just a teaching exploration. Teachers can also design their courses flexibly according to the characteristics of the curriculum. The interactive autonomous learning plays an important role in the teaching environment.

\section{Acknowledgment}

This study was funded by the National Programs for Science and Technology Development (grant number 2015BAK07B03) and Specific funding for education science research by self-determined research funds of CCNU from the colleges basic research and operation of MOE((grant number ccnu16JYKX022)).

\section{Reference}

[1] Sadaf A, Newby T J, Ertmer P A. Exploring pre-service teachers' beliefs about using Web 2.0 technologies in K-12 classroom [J]. Computers \& Education, 2012, 59(3): 937-945.

[2] Onah D F O, Sinclair J E. Measuring self-regulated learning in a novel e-learning platform: eLDa [C], Proceedings of the 15th Koli Calling Conference on Computing Education Research. ACM, 2015: 167-168.

[3] Sandeen C. Assessment's place in the new MOOC world [J]. Research \& practice in assessment, 2013, 8(1):5-12.

[4] Yang J., Gong. C., Yu J., Kinshuk, The Status and Trend of Research towards Smart Learning Environments -Interview Professor Kinshuk (ET\&S Editor), e-Education Research, 2015(05), $85-88$.

[5] Zimmerma B j.Becoming a self-regulated learner[J].Theory in practice,2002,41:64-67.

[6] Dabbagh N, Kitsantas A. Personal Learning Environments, social media, and self-regulated learning: A natural formula for connecting formal and informal learning[J]. The Internet and higher education, 2012, 15(1): 3-8.

[7] Blomberg G, Renkl A, Sherin M G, et al. Five research-based heuristics for using video in pre-service teacher education [J]. Journal for educational research online, 2013, 5(1): 90-114.

[8] Yan H, Xiong Y, Jiang Y. Production Practice and Thinking of Micro Class Video [J]. China Educational Technology \& Equipment, 2015( 2): 61-63. 